Andrea Semprini

\title{
La naturaleza en la televisión: imaginarios de la naturaleza y enunciación televisiva
}

(traducción de Antonella Fagetti)

\section{El corpus analizado}

Hace algunos meses me pidieron que analizara el conjunto de las transmisiones televisivas dedicadas a la "naturaleza" programadas en las redes nacionales. El corpus analizado en las páginas siguientes se compone de una serie de transmisiones televisivas grabadas en las redes del estado y en los networks privados. Se trata en particular de las transmisiones siguientes: Johnatan Reporter (Retequattro), L'Arca di Noé (Canale 5), Linea Verde (Rai Tre), Geo (Rai Tre), Gli speciali del National Geographic (Retequattro) y Gaia Progetto Ambiente. El análisis del corpus fue llevado a cabo en un doble nivel temático y enunciativo. La focalización en las prácticas discursivas tuvo como objetivo principal la determinación de los lazos semióticos que los diferentes simulacros enunciativos entretejen entre sí, en busca del establecimiento de un específico contrato (o pacto) de lectura o de escucha. El análisis del contenido temático de las diferentes transmisiones se centró en una serie de elementos que aparecieron como cruciales en la descripción y en la comprensión del tema "naturaleza". Tales elementos terminan por constituir el esqueleto con- 
ceptual, el mapa cartográfico de la geografía semántica del universo de la "naturaleza". El análisis fue llevado a cabo de manera transversal en relación a cada transmisión. No se trato tanto de dar cuenta del específico pacto enunciativo y del núcleo temático de cada emisión, como del abanico de las modalidades (es decir del paradigma, aunque no exhaustivo) a través de las cuales el medium televisivo trata el objeto "naturaleza". Tanto el análisis temático como el enunciativo tenían la finalidad de identificar posibles axiologías, es decir diversos modos posibles de construir el objeto "naturaleza" en las transmisiones televisivas, y las implicaciones ideológicas, éticas o antropológicas cristalizadas en cada una de ellas. En esta fase final, el corpus de las transmisiones analizadas tuvo un papel más de estímulo y de sugerencia, que de marco exhaustivo de la investigación. En este sentido, el abanico de los posibles axiológicos identificados es más amplio y no resulta enteramente asociable con las transmisiones observadas.

\section{La naturaleza como macrogénero discursivo}

Una primera dificultad encontrada en la organización del material televisivo concieme a una cuestión de clasificación y de definición: de clasificación, porque parece evidente que las llamadas transmisiones sobre la naturaleza mezclan un número impresionante de géneros y de "estilos" televisivos, todos importados de otros géneros, de otros mundos de referencia o de otras estrategias discursivas. En este sentido encontramos en el corpus - pero a menudo en la misma transmisión - mezclados géneros tan diversos como el documental, la película de divulgación científica, la entrevista, el servicio grabado especialmente, la transmisión en directo, la película de montaje, las escenografías con trasfondo realista (los llamados docudramas), las películas de viaje, la aventura. Aparentemente, por lo tanto, el discurso sobre la naturaleza se instala como parásito de un amplio abanico de géneros 
reconocibles y bien constituidos, que sin embargo le son teóricamente extraños. Por otra parte, es interesante observar que la única tentativa de constituir un real y verdadero género televisivo sui generis para hablar de la naturaleza, o sea los documentales ampliamente escenificados de las famosas series de Walt Disney de los años cincuenta y sesenta, están del todo ausentes del corpus analizado y, de manera más general, de toda práctica televisiva actual que concierne a la naturaleza. Carentes de definición, además, porque si bien es cierto que, por un lado, parece que se habla de la naturaleza exclusivamente a través de géneros que no le pertenecen, es, por otro lado, también cierto que resulta bastante problemático definir cuál es el objeto mismo de una transmisión sobre la "naturaleza". Los temas más diversos entran en la nebulosa "natural": desde los viajes de exploración hasta los parques nacionales; desde los problemas del ambiente mundial (ozono, efecto invemadero) hasta los del ambiente individual (prácticas alimenticias, dejar de fumar); de las investigaciones de etología al acaparamiento alimenticio en tiempos de guerra.

Tal indeterminación, tanto expresiva como temática, parece no deberse tanto a la casualidad de la constitución del corpus, como a una efectiva indeterminación del universo semántico y comunicativo del objeto "naturaleza". Es como si no se supiese o no se lograse determinar qué es la naturaleza y cómo se tiene que hablar de ella en términos enunciativos y comunicativos. Es en tal sentido que la "naturaleza" televisiva nos parece más que nada un macrogénero o, para usar un término de uso ya corriente, un "contenedor", un palimpsesto vagamente esbozado, una escalerita donde sólo algunos apoyos fuertes están establecidos y donde el grueso de la programación depende de las circunstancias (comunicativas) de las elecciones temáticas y de las estrategias enunciativas de las numerosas figuras implicadas en el intercambio. Tratemos, entonces, de dilucidar más precisamente estos apoyos fuertes, estas figuras recurrentes, aunque utilizadas con infinitos matices y variantes, estos sólidos anclajes en el interior del palimpsesto donde se esboza el informe discurso "sobre la naturaleza". 
Con este término entendemos, en el ámbito de la clásica oposición entre modum y dictum, el conjunto de los procedimientos estilísticos, retóricos y sintácticos que definen y constituyen el específico modum enunciativo de un discurso. Puesto que el fin de estas páginas no es mostrar en detalle los diferentes elementos que concurren en la formación de un modum enunciativo, nos limitaremos a describir y a comentar brevemente los principales estilos enunciativos del discurso sobre la naturaleza, tal como aparecen en el corpus analizado.

Discurso pedagógico. Se trata de un estilo que recubre esencialmente la esfera informativo-didáctica. La enunciación se quiere objetiva e impersonalmente neutral. El esfuerzo se centra en la transmisión de nociones, conjuntos de conocimientos. Para constituirse como tal, el discurso pedagógico debe necesariamente ser reconocido como discurso verdadero. En este sentido le es necesario recurrir a procedimientos específicos que aseguren la credibilidad, la verosimilitud y sobre todo la legitimidad de su decir. Otra importante característica del discurso pedagógico sobre la naturaleza, que lo diferencia de formas más canónicas de pedagogía, es la ausencia de finalidades instructivas que vayan más allá de la simple transmisión de conocimiento. El discurso pedagogico sobre la naturaleza es a menudo, en el corpus analizado, un discurso amoral, en el sentido de que se priva o se impide cualquier forma de generalización didascálico-apologética o alegorica de los conocimientos transmitidos. Una vez más parece interesante comparar la pedagogía naturalista actual con la de los años șesenta, de tipo alegorico-esopiano o bien con forma de apólogo moral. Este estilo enunciativo está particularmente presente en las transmisiones Johnatan Reporter, L'Arca di Noé y Geo.

Discurso objetivo o referencial. Aparentemente similar al discurso pedagógico, se diferencia de él en efecto de manera sensible y en aspectos importantes. Si también este aspira ante todo a la enunciación de un decir verdadero, tal verdad se quiere inscrita 
en la objetividad misma de la naturaleza y de la observación de ésta. Mientras que el fin pedagógico justifica una manipulación de la observación en vista precisamente de una verdad por construir (la del saber) para después poderla transmitir, el discurso objetivo se limita a mostrar, a hacerse medium transparente, mera unión entre el mundo natural a reproducir, y el espectador. La forma canónica de tal estilo enunciativo es el documental, mejor si está marcado semióticamente por atributos de historicidad ("Les presento ahora una filmación de 1975"), de no profesionalismo (imagen tambaleante, grano del negativo, montaje inexistente, etc.). Sin extendemos sobre el hecho, bien conocido, de que la referencialidad es el resultado de una manipulación, exactamente como ocurre en todos los demás estilos enunciativos, se notará sin embargo la insistencia, en el ámbito de este estilo, de las figuras y de las prácticas del mostrar. Se diría que la exasperación del acto de la visión y de sus diversas posibilidades constituye un rasgo específico de este tipo de discurso. Nótese, por ejemplo, la utilización del mostrado mostrante (la etologa Diane Fossey mostrada mientras muestra a los gorilas, o mientras muestra a los estudiantes lo que debe ser mirado) o la utilización del mostrado mirante (los guardabosques mostrados mientras observan el parque con los binoculares, la antropóloga indonesia Birute mostrada mientras observa las acrobacias de los orangutanes en los árboles). Este tipo de estilo enunciativo se encuentra a menudo, dentro del corpus analizado, en transmisiones como Gli speciali del National Geographic, Johnatan Reporter y El L'Arca di Noé.

Discurso cómplice. Se trata de una modalidad enunciativa dirigida principalmente a establecer una relación fuerte y mutuamente reconocida entre enunciadores y enunciatarios. Las implicaciones en términos de estrategia enunciativa serán descritas en el capítulo siguiente. Limitémosnos aquí a ofrecer las características del discurso cúmplice. El discurso cómplice está diseminado por marcas dirigidas por un lado a la definición del tipo de complicidad y por otro a la explicitación de tal complicidad a los partici- 
pantes de la comunicación. La complicidad necesita, en efecto, ser definida porque puede asumir, y de hecho asume, en el discurso de los media, varias formas. Puede haber una complicidad basada en el saber, donde los dos participantes se sienten cómplices porque conocen cosas que otros no conocen; así, puede haber una complicidad basada en el hacer, en el sentir o en el compartir determinados valores. Una vez definida, tal complicidad debe ser explicitada en terminos relacionales para afirmar claramente que se es cómplice, que se es consciente de ello y que se quiere continuar siéndolo. En este sentido el discurso cómplice es rico en afirmaciones que dan por descontada la adhesión del escucha, en utilizaciones de formas impersonales inclusivas y plurales ("se sabe" utilizado en el sentido de sabemos), de marcas paralingüísticas (guiños, silencios elocuentes, elipsis verbales). Resulta interesante observar que el discurso cómplice no es utilizado con frecuencia en las transmisiones analizadas. Parece que las modalidades practicadas prefercncialmente por la enunciación televisiva sobre la naturaleza se confían más frecuentemente al estilo referencial o al estilo pedagógico. Las únicas transmisiones donde es posible encontrar trazas de discurso cómplice son Gli speciali del National Geographic (pero sólo en lo que concierne a las intervenciones de la comentarista italiana), y de L'Arca di Noé. Es difícil decir si la ausencia de búsqueda de la complicidad está ligada a la evolución sociocultural (esto sería típico del discurso televisivo sobre la naturaleza hecho en el pasado) o a la necesidad, sentida más o menos claramente por los diferentes emisores, de preparar hoy una complicidad que por el momento no existe. Se diría que una comunidad de intentos y de valores en torno al tema de la naturaleza está todavía por venir.

\section{Estrategias enunciativas y lectores implícitos}

Cada uno de los tres estilos enunciativos descritos en el capítulo anterior se inscribe al interior de una estrategia enunciativa y con- 
figura un simulacro de enunciatario. Dicho en otros términos, cada estilo discursivo es utilizado como instrumento, esencial pero no único, en la edificaçión de una particular estrategia que pone en relación al productor con el receptor del discurso. Poner en acto una estrategia enunciativa significa entonces, entre otras cosas, producir, en el texto mismo, hipotesis sobre las necesidades, sobre las expectativas, sobre los gustos, sobre las competencias del futuro usuario del texto. Cada texto, entonces, implica un lector y tal implicación es el resultado de una manipulación o estrategia enunciativa. Cada estilo enunciativo es por lo tanto asociable a una particular estrategia y a un lector específico implícitó.

El discurso pedagógico construye una relación asimétrica, donde los dos miembros de la comunicación, el enunciador y el anunciatario, no se encuentran en un plano de paridad sino en posición de dependencia no recíproca. Quien recibe la comunicacion es por definición considerado privado de cierto saber, y de cierto tipo de información, que el enunciador se encarga de transmitirle. Hay que notar que en la estrategia pedagógica el receptor está construido como necesitado de saber, pero no necesariamente como consciente de manera explícita, o como solicitante de tal información. La estrategia pedagógica postula, por así decirlo, que la transferencia del conocimiento debe efectuarse, así el destinatario lo quiera o no. El objeto del conocimiento, en nuestro caso "la naturaleza", se encuentra de este modo valorizado a priori, digno de ser transmitido sin explicar las razones de tal información. El lector, o el espectador, implícito en tal estrategia es entonces un escucha construido no sólo como privado de información, sino también necesitado de ella. La asimetría principal entre ambos miembros de la comunicación se da en este nivel: uno decide lo que es bueno que el otro sepa mientras el otro queda prefigurado como alguien que está de acuerdo a priori con tal decisión, aunque no necesariamente consciente de ello.

El discurso referencial construye una relación paradojica en la que uno de los dos miembros de la comunicación se construye como ausente, mero trámite entre lo real y el espectador. La para- 
doja de la relación consiste entonces en el hecho de que el enunciador trata de desaparecer a través de una estrategia de la transparencia y de la mediación simbolizada, como hemos visto, por las metáforas de la visión. En este sentido el papel del enunciador es el de poner el saber a disposición del enunciatario, pero no el de valorizarlo como digno, a priori, de transmisión. El matiz es importante porque tiene dos consecuencias en términos de estrategia enunciativa global y de construcción del objeto "naturaleza". La primera es que en el ámbito de tal estrategia el objeto parece contar más que la relación, o, si queremos, el representado parece contar más que el representante. La "naturaleza" puesta en escena obtiene la calificación de única protagonista y de objeto de valor en sí (mientras que en la estrategia pedagógica la "naturaleza" está en función de la relación, pedagógica precisamente). La segunda consecuencia es que en el interior de esta estrategia el enunciatario es dejado libre de decidir si está o no interesado o de acuerdo con el tipo de acercamiento propuesto. La naturaleza aquí no está propuesta como un tema del cual el enunciador ya ha decidido la importancia (como en el caso de la estrategia pedagógica), sino como un simple pedazo de lo real que el enunciador es llevado a observar y a aceptar si lo considera oportuno. Se notará que todo esto es obra de una manipulación semiótica, de la misma manera que en la estrategia pedagógica, y que la libertad de elección y el respeto del enunciador están construidos por el propio enunciador y no son objetos del mundo real.

El discurso cómplice construye una relación simétrica y próxima. La relación entre los dos miembros de la comunicación se establece en un plano de paridad y de intercambio recíproco. En esta estrategia enunciativa el acento está puesto principalmente sobre la rclación misma, en su naturaleza, en su solidez y en las condiciones de su duración. En términos de manipulación semiotica es importante notar que esta estrategia postula a los dos miembros de la comunicación como próximos entre sí y en un plano de paridad. La proximidad puede ser de naturaleza varia: axiológica, y entonces los dos miembros compartirán los mismos 
valores; cognoscitiva, y entonces se tratará de los mismos' conocimientos a ser compartidos, etc. En términos de construcción del espectador implícito, se notará que la estrategia de la complicidad tiende a segmentar netamente las tipologías de recepción. Construyendo un simulacro de espectador implícito ya dotado de una serie de competencias, a determinar caso por caso, es evidente que todos los lectores que consideran que no comparten tal conjunto cerrado de rasgos característicos tenderán a rechazar, más o menos netamente, el simulacro propuesto. Por la misma razón, quien por el contrario considere que comparte con ese simulacro todos los rasgos propuestos, se adherirá fuertemente a la propuesta enunciativa. Es solo en este caso que se instala una relación de complicidad. Se notará, por otro lado, que las dos actitudes son complementarias. La complicidad implica estructuralmente la exclusión. Recordemos que la estrategia enunciativa de la complicidad es la menos presente en el corpus analizado donde predominan, por el contrario, las estrategias pedagógicas (con diferentes variantes) y las estrategias diferenciales.

\section{La figura del experto}

El conjunto de las transmisiones sobre la naturaleza que hemos observado presenta la característica, común a todo el corpus, de un recurso sistemático a todo tipo de experto. En términos semioticos, la figura del experto ocupa un papel crucial en la constitución de una estrategia narrativa y discursiva. El experto puede funcionar como marca veridictiva del decir verdadero del discurso, y en este caso se constituirá en garante de un discurso producido por otros; o puede asumir directamente la producción del discurso mismo, y en este caso calificará el discurso entero con su propia figura. En esta segunda hipótesis el experto, más que certificar, se coloca como fuente caracterizada de la legitimidad de un discurso. Es más bien esta segunda estrategia la que parece prevalecer en las trasmisiones observadas. Si el funcionamiento de la figura del ex- 
perto en el nivel narrativo es entonces bastante clara, podemos observar que existen en el nivel discursivo variadas figuras de experto y que cada figura tiende a caracterizar el estilo enunciativo de un discurso según su propio tipo peculiar d'expertise. El corpus analizado presentá las siguientes figuras de experto:

El experto cognoscitivo. Se trata de un rol a menudo tematizado en los términos del científico y del investigador (cfr., en el corpus el oncólogo Veronesi, el enologo, varios entrevistados). Él es un experto sobre todo porque sabe, detenta un saber que los otros personajes de la narración no poseen, y puede poner a los demás en condición de saber cuál es la justa solución. La figura del experto cognoscitivo naturalmente está utilizada con frecuencia en el discurso pedagógico por la fuerte legitimidad que sabe' atribuir al discurso mismo y por el efecto de asimetría que él induce ("Pero diga, profesor, ¿qué debemos comer?).

El experto por experiencia. Este papel es susceptible de tematizaciones diferentes. Con referencia al corpus, encontramos el vigneron sudafricano, el guardabosque, el marinero, etc. En este caso son la costumbre y la práctica las que garantizan la legitimidad y la credibilidad del experto. Él si sabe, sabe porque hace. Es siempre un hacer que estructura su saber, saber que a su vez no se ofrece como corpus teórico de preceptos o de teorías, sino como conjunto de ejemplos y simple imitación. Clásicamente este experto habla poco y se mueve mucho. Véanse, por ejemplo, en el corpus los varios guardabosques que muestran, hacen tocar, mueven, indican dónde y qué mirar, o simplemente hacen lo que se debe hacer e invitan al interlocutor a imitarlos. La figura definitiva del experto por experiencia es el animal mismo. ¿Quién sabe más que él sobre la naturaleza y sobre él mismo? Nos encontramos así frente a la interesante paradoja en la cual el así llamado experto (en el caso de la etóloga Diane Fossey) tráta de imitar al animal, al que se le reconoce un estatuto de metaexperto. Regresaremos sobre las implicaciones del uso de tal figura de experto en en el parágrafo 9. Esta figura de experto es utilizada sobre todo en el discurso objetivo-referencial, por su capacidad 
de construir un experto "natural" el cual, aunque no menos "experto" que otros expertos, hace implícito su rol narrativo y parece producir la legitimidad y credibilidad por el simple hecho de existir en la narracion (pero obviamente si existe es porque alguien to puso ahí).

El experto por pasion. Esta figura de experto puede ser tematizada tanto por personajes genéricos (el naturalista, el ecologista, el comentarista) como por personajes específicos. Lo que lo caracteriza, de todos modos es la pasión que pone en lo que dice 0 hace y que hace creíble y legítimo su decir y hacer. Hay que notar que el experto por pasión no detenta necesariamente un saber de orden teórico; su actuar correcto o el tomar decisiones correctas nace de una suerte de verdad interior que la pasión hace brotar. En este sentido, el experto por pasión contribuye a la construcción de un discurso de la complicidad y de la proximidad. Su falta de saber y de experiencia (posible, aunque no necesaria) lo hacen más cercano al espectador y no plantean problemas de asimetría, a menos que naturalmente el enunciatario niegue legitimidad a la pasión en tanto forma d'expertise (en este caso el experto será percibido como veleidoso o como fanático). En el corpus analizado las figuras de expertos por pasión parecen raras (un ejemplo son las presentaciones de los especiales del National Geographic). Como sucede a menudo, algunas temátizaciones de la figura del experto pueden presentar sincretismos entre dos 0 más de las figuras fundamentales. Así, por ejemplo, el explorador (Johnatan) puede ser considerado como una combinación de experiencia y pasión, y Diane Fossey o Birute una combinación de saber y pasión.

\section{Discurso sobre la naturaleza y sistemas temporales}

En el interior del corpus analizado es posible discemir diferentes referencias al tiempo y a la temporalidad. Tales referencias nos parecen recurrentes, y por ende importantes en tanto constituyen 
un ulterior elemento del esqueleto que estamos construyendo para llegar a un censo de las diversas representaciones de la naturaleza construidas por el medium televisivo. Parece que el mundo natural (comprendiendo en esta definición, jay de mr!, vaga, tanto la "naturaleza", como los animales, como los pueblos no industrializados, etc.) estuviera caracterizado, cuando no constituido, por una temporalidad diferente de la temporalidad del mundo contemporáneo/industrial. La diferencia entre las dos temporalidades se articula sobre varias posiciones categoriales, pero todas confluyen en una macrocategoría que termina con oponer la lentitud a la rapidez, una temporalidad dilatada y rarefacta a una temporalidad comprimida y concentrada. Tratemos de detallar estos aspectos.

Temporalidad ć́clica vs temporalidad lineal. El tiempo de la naturaleza es un tiempo cíclico y siempre renovable. Se caracteriza por el hecho de recorrer infinitamente el mismo movimiento. El tiempo del mundo industrial es un tiempo lineal y acumulativo. Se caracteriza por el hecho de desarrollarse sin nunça regresar al recorrido ya trazado, y por una idea de progresión que es constitutiva de la noción misma de evolución. Hay que notar que lo cíclico de la temporalidad natural es a fin de cuentas función de la perspectiva temporal adoptada: si se mide el tiempo en millares de años, el ciclo natural pierde sentido y se entra en una lógica evolutiva. Mas es la escala la que ha cambiado.

Inalterable vs alterable. La temporalidad de la naturaleza es una temporalidad que obedece a leyes inmutables.y como tal no puede incorporar modificaciones o alteraciones sin ser completamente desestabilizada. Es en este sentido que su temporalidad es constitutiva. Por el contrario, la temporalidad humana es por definición modificable y discontinua. Ella sufre aceleraciones, retardos, paradas, etc. Temporalidad natural y humana son entonces presentadas como opuestas en el plano de la flexibilidad, de la capacidad de adaptación.

Lentitud vs instantaneidad. El tiempo natural se define como lento, largo, casi interminable. Se opone a un tiempo humano hecho de instantes, de rapidez fulmínea. Mamá osa concibe cada 
cinco años, se necesitan tres años para readaptar un orangután a la vida natural y veinte años para repoblar con 400 cabras monteses una área fáunica. Esta lentitud natural entra en colisión con la temporalidad humana, a la cual le bastan pocos segundos para matar a mamá osa, pocos meses para exterminar una manada de animales y pocos años para arrasar una selva.

La estructuración de esta oposición entre temporalidad natural y temporalidad humana tiene una importante consecuencia en la constitución del imaginario mediatizante de la naturaleza. En primer lugar subraya la incompatibilidad de los dos sistemas. Esto implica que sólo dos posiciones son configurables en la confrontación entre los dos mundos y por tanto entre las dos temporalidades: una relación de preservación total o una relación de inevitable devastación. La preservación se configura en la lógica de la reservación, del oasis o de la zona protegida. Son fragmentos de temporalidad sustraídos para siempre a la temporalidad humana y preservados en la medida en que son delimitados y aislados. La lógica de la devastación implica el reconocimiento de que toda interacción con la naturaleza es de carácter destructivo, por ser radicalmente incompatible. Hay que notar que la lógica de la devastación puede ser adoptada por actitudes ideologicas opuestas. En una caso (ecologismo militante) será para denunciarla y combatirla, en el otro (partidarios de la inevitabilidad del desarrollo) para actuar de manera fatalista según una lógica de la incompatibilidad en la que la naturaleza está llamada a sucumbir frente a las necesidades del desarrollo económico e industrial.

Una última consideración sobre la temporalidad, pero la de las transmisiones televisivas y no la de la naturaleza. Se notará que todas las transmisiones (con dos excepciones significativas) hablan de naturaleza o en pasado, como cuando muestran documentos históricos o de todos modos fechados, o en presente. Se trata casi siempre en este caso de un presente atemporal, que no tiene nada que ver con una lógica de contemporaneidad que instituya un paralelo entre el hoy de la transmision (que es un hoy sin ayer ni mañana) y el hoy del espectador, este último obviamente cala- 
do en la dinámica de la temporalidad real. El futuro está completamente ausente de la temporalidad de las transmisiones naturalistas. Gaia Proyetto Ambiente constituye una excepción (conjuntamente, pero en menor medida, con Linea Verde). Sólo la mención de la noción de proyecto instituye una temporalidad proyectada hacia el futuro e inscribe la problemática ambiental en una lógica de programación y de largo término (los dos significados del término proyecto).

\section{El espacio natural: los confines de la naturaleza}

También la noción de espacialidad puede ayudarnos a enfocar los imaginarios naturales propuestos por el medium televisivo. Mas en particular, es la sobreposición del concepto de espacialidad al de temporalidad que permite una definición más fina del objeto "naturaleza". En efecto, en casi todas las transmisiones televisivas analizadas, el espacio natural representado parece radicalmente extraño y lejano al espacio humano (en el sentido general definido anteriormente). El espacio natural es un espacio siempre lejano. Sobre todo geográficamente, porque se trata de Alaska septentrional, de Mali, de Borneo o de Rwanda. Pero también temporalmente lejano, porque concieme a cosas sucedidas hace decenas de años atrás (cfr., los especiales del National Geographic o los viajes del explorador Guilmaux). Tal dépaysement geográfico-temporal provoca un efecto de extrañamiento conceptual y cultural. El objeto "naturaleza" parece un objeto radicalmente extraño, un objeto de representación que no nos concierne y no nos interpela en tanto potenciales usufructuarios o pobladores de tal ambiente, sino más bien en tanto espectadores, observadores no implicados y distantes de una èscenografía natural. En efecto, la particular espacialidad de la naturaleza, representada por las transmisiones televisivas analizadas, sugiere profundamente tal nocion de ficcionalidad. Los espacios naturales nunca se colocan ni en un contexto geográfico más amplio, ni mucho menos en un contexto geopolítico o geosocial. 
La "selva pluvial de Rwanda" o "la isla de Kodiak" se transforman así en puros lugares imaginarios, otras tantas Lilliput dotadas de interesantes características, de trazos propios en las que la voz fuera de campo nos entretiene, que observamos con interés y curiosidad para después regresarnos a casa. Como al Magic Kingdom de Disneylandia. La cuestión entonces de la relación y de la interrelación entre ambiente natural y ambiente humano se deja completamente de lado. Las zonas naturales observadas y descritas no tienen fronteras, no son cercanas o lejanas de nada porque fluctúan en una especie de geografía "mediológica" del todo ficticia. Se confirma, en el análisis espacial, la intuición aparecida durante el análisis de los sistemas temporales. La naturaleza representada por las transmisiones sobre la "naturaleza" es una naturaleza radicalmente otra, una "naturaleza" erradicada, descontextualizada, objetivada y despasionalizada. Una naturaleza reconstruida según la logica del documento histórico y por lo tanto comunicada como información objetiva (estilo referencial) o como elemento de aculturación y aprendizaje (estilo pedagógico). La naturaleza televisiva se convierte en fábula: "Había una vez, en una selva pluvial de Rwanda, una mujer que vivía en una cabaña..."

\section{Naturaleza y cultura: la buena distancia}

Los últimos dos capítulos han mostrado la recurrencia de una problemática crucial en el interior de la representación televisiva de la naturaleza: la de la relación entre naturaleza y contexto y también la más general de la atribución de los roles naturales y culturales. Nos parece que la problemática se enfrenta, o mejor se rodea, a través de una triple estrategia de simplificación, de segmentación y de desrealización.

Simplificacion. La estrategia de la simplificación es actuada reduciendo progresivamente los elementos susceptibles de perturbar una descodificación inmediata y no problemática del objeto naturaleza. La naturaleza es por así decirlo iconizada, reconduci- 
da a su representación canónica y reconocida. Una pradera será el icono de una pradera, un oso el icono de un oso, etc. En este sentido un análisis más profundo de los documentales naturalistas permitiría reseñar a los topoi que "hacen" naturaleza, es decir que hacen creíble, precisamente porque lo han iconizado, el objeto "naturaleza". Pensemos por ejemplo en el combate de los ciervos, en la ferocidad de mamá osa que defiende a sus pequeños, etc.

Segmentación. Se trata de una estrategia complementaria a la de la simplificación. Consiste en separar las temáticas y en presentar una sola a la vez. Así, cuando el tema es el animal, no se tratará más que de animales; cuando se habla de grupos étnicos, éstos se muestran mediante cantos y danzas, raramente en inte- racción con el contexto natural, también fundamental en este tipo de culturas. La noción de ecosistema parece estar ampliamente ausente de la mayor parte de las representaciones analizadas de la naturaleza. Significativamente, cuando un ser humano (en el caso específico una mujer), se introduce furtivamente en el documental, ella se renaturaliza asumiendo los comportamientos de los animales que estudia.

Desrealización. Esta tercera estrategia concieme al efecto de extrañamiento generado por las representaciones de la naturaleza. Simplificada, encajada e iconizada. Separada del contexto social, político y geográfico. Situada en un tiempo y en un espacio no precisados, y en todo caso radicalmente diferente del tiempo y del espacio del espectador, la naturaleza se convierte en una figura abstracta, no reductible a ningún territorio de lo experimentable. Proyectada en una dimensión imaginaria, ésta al mismo tiempo se precisa (como icono hiperreal) y se disuelve (como sistema de referencia).

No podemos dejar de notar, al concluir el capítulo, que el concepto de ambiente, entendido como conjunto interactivo de naturaleza, vida animal y presencia del hombre, todo en un contexto socioeconómicamente precisado, en un momento histórico dado y en una localización geográfica definida, está ampliamente ausente de las representaciones de la naturaleza contenidas en las trans- 
misiones analizadas, aunque ampliamente presentes en las generalizaciones de apertura y clausura, y en los discursos de los varios comentarios y comentaristas. Unica excepción es la transmisión Linea Verde y, en parte, Gaia.

9. ¿Cuántas naturalezas tiene la televisión?

Muchas, sin duda, pero seguramente no demasiadas, puesto que el análisis evidenció un recurso sistemático a algunos sistemas de representación y de enunciación en detrimento de otros, practicados en el pasado o no practicados del todo por el medium televisivo. En este capítulo conclusivo trataremos de reseñar sintéticamente una serie de posibles modos de representación de la naturaleza. Recordemos, como afirmamos al principio, que tales representaciones se inspiran sólo parcialmente en el corpus analizado, considerado en este caso más como una sugerencia que como un paradigma de referencia. La misma consideración vale a la inversa. $\mathrm{El}$ hecho de que ciertas representaciones de la naturaleza no estén presentes en el corpus, no autoriza de ninguna manera a afirmar que ellas no pertenecen al lenguaje de la "naturaleza" televisiva. Eso resulta posible pero, ante la ausencia de un corpus exhaustivo y precisamente definido, permanece indemostrable.

Naturaleza cognoscitiva. Este término ha sido usado con frecuencia en el curso del análisis. Él sintetiza una representación de la naturaleza en la cual ésta aparece esencialmente como objeto de estudio, texto para descubrir e interpretar, pero con fines de instrucción y de enriquecimiento cultural. La dimension cognoscitiva de la naturaleza parece ser propuesta como un fin en sí, un saber valorizado en cuanto saber y separado de un hacer y de un sentir. Recordemos que la segmentación y la departamentalización de la naturaleza parece ser un rasgo característico del modo televisivo de construir el objeto "naturaleza".

Naturaleza pragmática. En este caso la naturaleza es sobre todo el resultado de un hacer y de la acción transformadora del hom- 
bre. La naturaleza se convierte en el campo de inscripción de prácticas múltiples. Tales prácticas pueden ser destructivas (tala de selvas), criminales (vaciado indiscriminado de venenos), tradicionales (caza y recolección) o de carácter agrícola (viñedos sudafricanos). Lo que es común a todas estas prácticas, así sean "buenas" o "malas", es el hecho precisamente de ser prácticas y de establecer entonces una dinámica de interacción entre el hombre y la naturaleza. La formulación de un concepto de "ambiente" está con seguridad más fácilmente conectado a este tipo de representación del objeto "naturaleza".

Naturaleza patémica. En este modo de representación la naturaleza se convierte en fuente de emociones y suscita sentimientos, más que acciones o reflexiones. El estilo de representación aspira entonces, aristotélicamente, a la conmoción del espectador, a suscitar en él sentimientos de temura, de admiración, de inquietud, etc. La naturaleza deviene aquí un espectáculo maravilloso y terrorífico, tanto en su espectacularización como en su patemización. Como ya vimos para la naturaleza cognoscitiva, también aquí la estrategia pasional no se prolonga en una estrategia pragmática o cognoscitiva. La emoción es fin en sí misma, no es nunca, o sólo rara vez, el mecanismo para inducir a la acción o a la cognición.

Naturaleza frágil. Esta representación de la naturaleza pone en evidencia dos rasgos atribuidos al mundo natural: su radical alteridad y su consecuente vulnerabilidad a todo tipo de interacción, que termina inevitablemente por configurarse como ataque 0 amenaza. En el capítulo sobre la temporalidad del mundo natural y del mundo humano discutimos en detalle los mecanismos de esta separación. Lo que es importante recordar aquí son las implicaciones antitéticas de esta representación de la fragilidad natural: por un lado una logica proteccionista a ultranza, que ve en el aislamiento la sola protección eficaz; por otro lado, una lógica realista o fatalista que acepta la violación de la fragilidad natural como el precio inevitable del contacto entre los dos mundos.

Naturaleza autopoietica. Esta definición, tomada en préstamo de la biología vareliana, nos parece útil para etiquetar una repre- 
sentación de la naturaleza radicalmente opuesta a la de la fragilidad. Aquí la naturaleza está representada como capaz de evolucionar y transformarse, produciendo ella misma, en su interior, los mecanismos de ajuste a las modificadas condiciones extemas. Este acercamiento niega entonces la alteridad radical del mundo natural y se basa en la capacidad no sólo reactiva, sino sobre todo creativa y autopoietica de los sistemas vivientes. Tal representación de la naturaleza implica un cambio radical de perspectiva en las relaciones entre mundo natural y mundo humano. Por una lado ésta reniega la lógica de museificación y de proteccionismo presente en la representación de la naturaleza como frágil; por otro, libera implícitamente de rémoras o escrúpulos ambientalistas, subrayando la capacidad de la naturaleza de reaccionar activamente a las intervenciones externas.

Naturaleza autorregulada. Se trata de una representación de naturaleza muy cercana a la anterior, pero con algunas diferencias significativas. Mientras que en el caso de la autopoiesis el acento está puesto en la capacidad de la naturaleza de responder activamente, a través de mecanismos específicos, a la modificación del ambiente circundante, en el caso de la autorregulación la respuesta natural está configurada como esencialmente reactiva, mera reestructuración operada pasivamente con respecto a una acción proveniente del exterior. La diferencia, en terminos de implicaciones conceptuales, es entonces importante. La representación de naturaleza autorregulada muestra que si, por un lado, el objeto "naturaleza" no es inelástico es entonces frágil como cristal; por otro lado, éste no responde con paridad de armas a los ataques externos, sino sólo por reacción, por así decirlo, entrópica. El ejemplo típico es el de los animales o de las poblaciones amazónicas que autorregulan su comportamiento retirándose a zonas siempre más remotas, conforme el mundo humano avanza. Parece evidente que esta representación de la naturaleza, aun subrayando las capacidades reactivas del mundo natural, es menos susceptible de proporcionar fáciles coartadas, como es por el contrario el caso de la representación autopoietica. 
Naturaleza entomologica. Este modo de representación de la naturaleza está caracterizado por la elección de una escala particularmente aproximante, de una macrofocalidad natural. La "naturaleza" en este contexto pierde su identidad como fenomeno de conjunto y es fragmentada en una serie de acciones o de situaciones extremadamente detalladas y precisas. La presentacion recuerda entonces una lógica entomológica, preocupada mucho más por la precisión del detalle que por la significatividad del conjunto. El primer plano del rocío que recubre de perlas un hongo, de la orilla de una hoja, de la huella de un animal, se convierten en los rasgos característicos de este modo de representar a la naturaleza. El ave que agoniza sofocada por el petróleo, el huevo que se abre, el animal perseguido por el objetivo hasta el fondo de su guarida debajo de la tierra, son otros tantos ejemplos de representaciones entomológicas.

Naturaleza hipernatural. Se trata de una representación de la naturaleza inscrita en las prácticas de la modernidad sociocultural. La naturaleza es extraída de su contexto para ser normalizada, reacondicionada y reconstruida para el uso y el consumo del hombre. En la lógica hipernatural no se trata de sustituir completamente la naturaleza con artefactos de origen humano. Más bien se trata de "mejorar" la naturaleza inspirándose en ella, y de servirse de la tecnología para tal fin. Algunos ejemplos: las paredes para free climbers en vitrorresina que se instalan en los grandes parques citadinos, los cañones que crean la nieve artificial, las barreras rompeolas hechas de corales en lugar de cemento, etc. En la lógica hipernatural la naturaleza es al mismo tiempo fuente de inspiración (pensemos en las teorías neuromiméticas o biomiméticas en inteligencias artificiales) y objeto de mejoramiento. $\mathrm{La}$ alteridad natural se pone radicalmente en discucion a través de una disolución de la noción misma de frontera entre mundo natural y mundo humano. El operador de tal transformación es la tecnología. Una tecnología que ha asimilado la lección de los años sesenta y que ya no trata de ser alternativa a la naturaleza sino complementaria. El servicio sobre la sal killer de Gaia es al res- 
pecto emblemático. La solución al problema de los daños provocados por el uso de la sal como antihielo (un producto natural usado para combatir un fenomeno natural y que tiene efectos dañinos sobre el ambiente natural) vendrá de un compuesto químico, de producción meramente sintética, que presenta las mismas funciones de la sal (mejorada) sin las consecuencias dañinas para la naturaleza.

Naturaleza renaturalizada. Al extremo opuesto de la naturaleza hipernatural encontramos la naturaleza renaturalizada. Ésta se presenta como un desplazamiento de fronteras entre naturaleza y cultura en el sentido de la naturaleza. Mientras que en la representación de la naturaleza hipernatural es la naturaleza que la deviene cultural, en la representación de la naturaleza renaturalizada es la cultura la que se naturaliza. También esta noción parece estar fuertemente asociada con tendencias de la modernidad sociocultural. Los especiales del National Geographic muestran tanto la tentativa de reenseñar la naturaleza a un animal que perdio el contacto con esta, pero también el esfuerzo de hombres (o de mujeres) quienes para comunicar o para comprender la naturaleza tratan de volverse ellos mismos animales. Es como si el mundo natural encerrara un secreto y un lenguaje al cual no es posible acceder mediante traducciones o diccionarios sino s6lo por aprendizaje directo. Es impresionante observar los esfuerzos de Diane Fossey para convertirse, en el pleno sentido del término, en un gorila. Tal renaturalización pasa por una aceptación de todo lo que vimos con anterioridad caracterizar al mundo natural: el aprendizaje de una temporalidad expandida (metaforizada en términos pasionales como paciencia), el extrañamiento geopolítico, la desrealización y la pérdida, o la destrucción voluntaria, de los sistemas de referencia. Tal representación renaturalizada de la naturaleza muestra claramente su distancia con respecto a las otras más frecuentes formas de representación descritas. Frente a una naturaleza para observar (para aprehender), para admirar (para conmoverse) o para manipular (para servirse de ella), estamos aquí en presencia de la voluntad de hacerse naturaleza, sin duda 
para entender, pero sobre todo para poner en discusión nuevamente la posición cultural del animal-hombre. El extraordinario éxito en los Estados Unidos de la película de Kevin Kosner "Dancing with Wolves" ["Danza con lobos"] nos parece emblemático del vigor que ha vuelto a tomar tal tendencia, sustraída a las figuras especializadas de la etóloga un poco tocada o del héroe solitario. No sorprendería, en este sentido, que las escuelas de supervivencia para dirigentes, o los varios Camel Trophy o ParisDakar de los años 80, sean sustituidos en los años noventa por las escuelas de animalización y de mimetismo natural. Hipótesis sugestiva y para profundizar.

Una precisión a manera de conclusión. Los nueve imaginarios "naturales", o representaciones de la "naturaleza" descritos, deben ser considerados tipos ideales más que formaciones empíricas. Esto significa que raramente ellos están presentes en el medium televisivo con este grado de claridad y de coherencia. Como ocurre inevitablemente para cada tipología, son los fenomenos sincréticos y espurios los que predominan en la realidad. Si esto es cierto en el nivel temático, lo es aún más en el nivel enunciativo y mediático, donde las cosas se complican de manera desmedida y donde la polisemia y la polifonía del discurso hacen posible no sólo el sincretismo de numerosas representaciones de "naturaleza", sino también la cohabitación de representaciones diferentes en la misma transmisión, tomadas a cargo por diferentes figuras discursivas. El caso más típico de este fenómeno es aquel en el cual el plano de la enunciación articula una determinada representación de la naturaleza, y el plano del enunciado articula otra. Lo mismo vale para los mecanismos de toma de palabra y de oferta de palabra en el interior mismo del plano de la narración. Por tanto, nunca se estará suficientemente en guardia contra las generalizaciones apresuradas cuando se pasa de un análisis temático a un análisis discursivo, a fortiori si éste concierne al medium televisivo. 
Bibliografía

BARTHES, R., 1966, "Le classement structural des figures rétoriques". Le français moderne.

Bettetini, G., 1984, La conversazione audiovisiva. Problemi di enunciazione filmica e televisiva, Milán, Bompiani.

Dorfles, G., 1964, Artificio e natura, Turín, Einaudi.

Eco, U., 1971, Le forme del contenuto, Milán, Bompiani.

, 1979, Lector in fabula, Milán, Bompiani.

FERRARo, G., 1981, Strategie comunicative e codici di massa, Turín, Loescher

Greimas, A. J., 1976, Sémiotique et sciencies sociales, París, Seuil

Grermas, A. J. y Courtés, J., 1979, Sémiotique. Dictionnaire raisonné de une théorie du langage, vol. 1, París, Hachette

,- 1986 , Sémiotique. Dictionnaire raisonné de une théorie du langage, vol. 2, París, Hachette

LEonini, L., 1988, L'identità smarrita. Il ruolo degli oggetti nella vita quotidiana, Boloña, Il Mulino

PÉnInou, G., 1972, Intelligence de la publicité. Etude sémiotique, París, Laffont.

Ricoevr, P., 1983, Temps et recit, París, Seuil

TABBoni, S., 1984, La rappresentazione sociale del tempo, Milán, Angeli

Williams, Rosalind, 1982, Dream Worlds, Berkeley-Los Angeles, University of Califomia Press 